\title{
The perspective of primary health care pediatricians regarding childhood anemia and iron supplementation
}

\author{
Yanina Sguassero, M.D. ${ }^{a}$, Marcia M. Guerrero, M.D. ${ }^{b}$ and Mariana Romero, M.D. ${ }^{c}$
}

a. Center for Perinatal Studies of Rosario (Centro Rosarino de Estudios Perinatales, CREP), Rosario, Santa Fe, Argentina.

b. School of Medical Sciences, Universidad Nacional de Rosario, Rosario, Santa Fe, Argentina.

c. Center for State and Society Studies (Centro de Estudios de Estado y Sociedad, CEDES), National Scientific and Technical Research Council (Consejo Nacional de Investigaciones Científicas y Técnicas, CONICET).

E-mail address:

Yanina Sguassero, M.D.: ysguassero@crep.org.ar

\section{Funding:}

Ramón Carrillo-Arturo Oñativia Continuing Education Scholarship Program, granted by the National Ministry of Health of Argentina through the Health Research Committee (Comisión Nacional Salud Investiga).

Conflict of interest: None.

Received: 1-20-2017

Accepted: 7-26-2017

\begin{abstract}
Introduction. Iron deficiency anemia is common in low-and middle-income countries. According to the evidence, the impact of ferrous sulfate supplementation in the pediatric population is low. Our objective was to analyze the perspective of pediatricians regarding anemia and iron supplementation.

Populationandmethods.Qualitative, exploratory study. Semi-structured interviews were conducted with primary health care pediatricians from Rosario. Three core inquiry concepts were included: importance of this problem, clinical practice, and representations about iron supplementation. The analysis consisted in the systematization of the information collected by transcribing the recorded interviews and notes. Results. A total of 32 interviews were conducted. All interviewees considered anemia was a relevant problem. At present, anemia is associated with a poor-quality diet. Based on the findings, pediatric practice follows national standards. There is consensus that low adherence is a barrier for the clinical management of iron deficiency anemia. Pediatricians described concepts that are potentially beneficial for the local setting, including workshops on anemia and free provision of more flavorful iron supplements.

Conclusions. Iron deficiency anemia was considered a severe problem. In the primary health care setting, outstanding interventions included workshops and access to more flavorful iron supplements.

Key words: iron deficiency anemia, interview, primary health care, pediatrics, qualitative analysis.
\end{abstract}

http:/ / dx.doi.org/10.5546/ aap.2018.eng.21

To cite: Sguassero Y, Guerrero MML, Romero $M$. The perspective of primary health care pediatricians regarding childhood anemia and iron supplementation. Arch Argent Pediatr2018;116(1):21-27.

\section{INTRODUCTION}

According to the World Health Organization (WHO), anemia is a public health problem in most lowand middle-income countries. ${ }^{1}$ In these settings, the most common cause of anemia is iron deficiency, ${ }^{2,3}$ which may be summarized into two main issues: 1) it is the most prevalent nutritional deficiency and 2) children between 6 and 23 months old and pregnant women are the most vulnerable groups..$^{2,4}$

In Argentina, the National Survey on Nutrition and Health (Encuesta Nacional de Nutrición and Salud, ENNyS) 5 showed that the prevalence of anemia among children aged 6 months to 5 years was $16.5 \%$, and that it increased to $35 \%$ in the group aged 6-23 months. A study conducted in Rosario ${ }^{6}$ in approximately 300 children younger than 42 months found that the overall prevalence was $40 \%$. The protective effect of maternal adherence to iron administration against the risk for anemia in their children was described as an unprecedented finding.

The evidence suggests that the impact of ferrous sulfate supplementation in the pediatric population is low. ${ }^{7,8} \mathrm{~A}$ qualitative study carried out in different Argentine provinces showed that the attitude of health care providers towards the visualization of anemia translated into the relevance given to iron supplementation. ${ }^{9}$ Medical practice is not oblivious to the historical conditions in which it takes place. ${ }^{10}$ Although academic training has its own rules aimed at preventing interference in scientific knowledge acquisition, it is legitimate to think it is influenced by the changes in society 
and culture. In addition, it is worth noting that, in our setting, there is a tendency to believing that "if a child is growing well, he/she does not need iron".

The objective of this study was to know and analyze the perspective of primary health care (PHC) pediatricians regarding the erection of anemia as a health problem and oral iron supplementation as one of the available interventions for anemia prevention and management.

\section{POPULATION AND METHODS}

This was an observational, exploratory study conducted in the city of Rosario, Santa Fe (August-December 2014). Health centers were selected based on the recommendations made by the Municipal Department of Primary Health Care. The investigation was introduced to the coordinators of the participating centers and then pediatricians were invited to take part in the study.
Data were collected based on semi-structured interviews with pediatricians and observation. ${ }^{11}$ Also, in order to outline the professional profile of the sample population, a card including some of the outcomes of a survey administered to pediatricians was completed. ${ }^{12}$

An interview including 13 questions was developed; its domains were defined based on a local study's main findings. ${ }^{6}$ The core inquiry concepts were: 1) assessment of anemia and identification of groups at a higher risk, 2) level of heterogeneity in clinical practice in relation to iron deficiency anemia diagnosis, prevention, and management, and 3) representations about oral iron supplementation and maternal adherence (see Annex 1). Representation was defined as information, opinions, and attitudes regarding a specific object that contributed to building a common social reality. ${ }^{10}$

An assistant investigator experienced in the administration of data collection instruments was responsible for interviews. The interviewer's

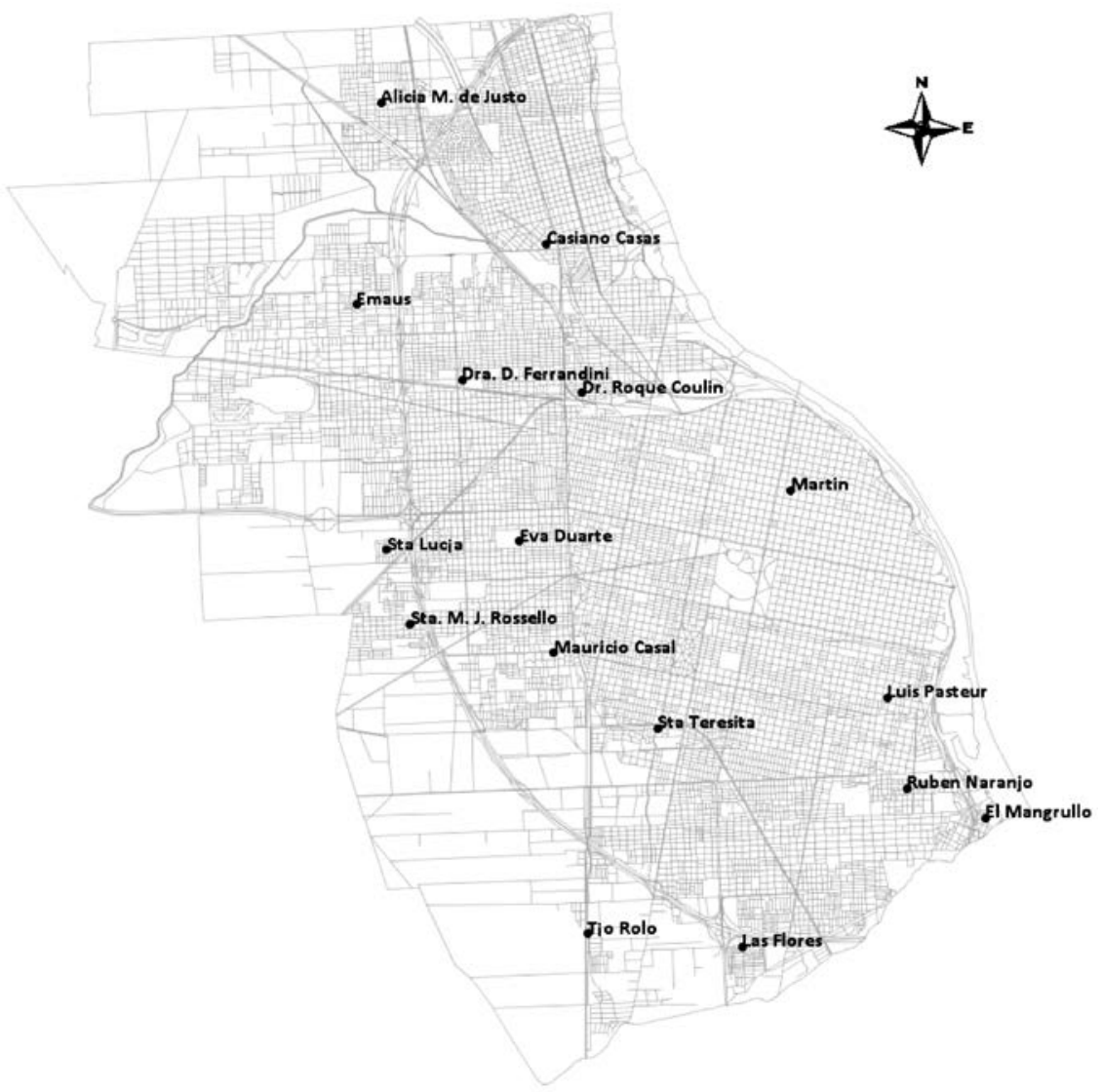


training included two role-playing simulations that helped to adjust the interview conduct (tone of voice, intonation of questions, duration and timing of breaks, etc.). In addition, and for instrument adjustment purposes, four pilot interviews with pediatricians from the public health sector were recorded and used to improve the question guide. Interviews were conducted in the pediatrics outpatient office according to a previously agreed schedule.

Interviews were recorded, but if a participant did not agree to be recorded, notes were taken. Information was systematized by transcribing the recorded interviews and notes. This was done once the data collection had ended and all transcriptions were available. Then, a data reduction process was started to differentiate central or fundamental concepts from secondary ones. Data reduction was done manually in a word processor and supported by double-entry tables (question/interviewee). Then, using selective text segment retrieval, contradictions / exceptions were identified and answer patterns were established for each question. Lastly, categories were determined and core concepts were developed to favor interpretations based on the proposed objectives. ${ }^{11}$

The authorization of the Department of Primary Health Care was obtained, and the Research Ethics Committee of the Secretary of
Health of the Municipality of Rosario granted its approval on August $6^{\text {th }}, 2014$. A written informed consent was obtained.

\section{RESULTS}

A total of 32 pediatricians from 16 municipal PHC centers were interviewed (Figure 1). Only one pediatrician refused to participate. Most interviewed pediatricians were women who worked 25-36 hours per week (Table 1). Except for a couple, all participants agreed to be recorded during the interview, which lasted an average of 20 minutes.

\section{Anemia as a challenge for public health}

Interviewees agreed that anemia was a relevant problem in Argentina. In their opinion, anemia is a common pathology in the pediatric population attending health care centers ("...I'd say it's an ancient problem, I mean, it's a common diagnosis we see all the time at the office...", interview no. 3). In spite of this statement, pediatricians did not have reliable data available to estimate the percentage of children younger than 24 months who had anemia. The modal value referred by those who attempted to establish a number was 40\% (20-70\%).

When asked about risk groups, in addition to traditional groups such as preterm newborns, low birth weight newborns, and breastfeeding

TABLE 1. Characteristics of interviewed pediatricians based on their years of professional experience

\begin{tabular}{|c|c|c|c|c|}
\hline Outcome measures & $\begin{array}{c}\text { Total sample } \\
(n=32)\end{array}$ & $\begin{array}{c}\leq 10 \text { years of experience } \\
(n=10)\end{array}$ & $\begin{array}{c}11-20 \text { years of experience } \\
(n=13)\end{array}$ & $\begin{array}{c}>20 \text { years of experience } \\
(n=9)\end{array}$ \\
\hline Female sex & 29 & 10 & 13 & 6 \\
\hline Pediatric subspecialty & 8 & 1 & 3 & 4 \\
\hline \multicolumn{5}{|l|}{ Rosario districts } \\
\hline Center & 1 & 0 & 0 & 1 \\
\hline North & 9 & 2 & 2 & 5 \\
\hline Northwest & 2 & 1 & 1 & 0 \\
\hline West & 4 & 2 & 2 & 0 \\
\hline Southwest & 10 & 3 & 4 & 3 \\
\hline South & 6 & 2 & 4 & 0 \\
\hline \multicolumn{5}{|l|}{ Position in PHCC } \\
\hline Pediatrician & 29 & 10 & 11 & 8 \\
\hline Coordinator and & & & & \\
\hline pediatrician & 2 & 0 & 1 & 1 \\
\hline Other & 1 & 0 & 1 & 0 \\
\hline \multicolumn{5}{|l|}{ Weekly hours } \\
\hline$\leq 24$ & 3 & 0 & 1 & 2 \\
\hline $25-36$ & 29 & 10 & 12 & 7 \\
\hline \multicolumn{5}{|l|}{ Working outside the } \\
\hline PHCC & 14 & 1 & 7 & 6 \\
\hline
\end{tabular}

PHCC: primary health care center. 
infants, interviewees mentioned children whose families had inadequate eating habits or who received insufficient iron from diet ("Well, in the setting where I work, i.e., primary health care..., in recent years it has been associated with poor nutrition rather than undernutrition... at least in the past eight or nine years, when I was trained in pediatrics, you'd see it in association with undernutrition, you'd see malnourished children with a very severe anemia; however, now I practically see no undernourished kids but I have a lot of anemia cases, and it's associated to undernutrition or you may even see obese children with anemia", interview no. 9).

Spontaneously, some interviewees gave their opinion about anemia diagnosis using a blood test (Table 2).

\section{Prevention and management of childhood anemia}

In a hypothetical scenario where it would be necessary to prescribe iron, we asked for the usual explanations for such prescription. All participants referred that they prescribed iron in prophylactic doses. As expected, age was the most common determining factor, followed by gestational age or birth weight, and type of child feeding. Among preterm newborns, supplementation started at 2 months old or even earlier. Among term newborns, iron was indicated approximately at 4 months old but if the infant was exclusively breastfed, it could be delayed for some time. Table 3 includes the explanations that were usually given when indicating ferrous sulfate. Almost all participants $(28 / 32)$ provided advice on how to improve iron absorption. Half of interviewees informed mothers of the potential side effects and clarified that it was a long-term treatment. A third of participants mentioned that they indicated folic acid for anemia management. Only a few (8/32) referred that they also explained why it was important for the child to receive iron.

\section{Control of oral iron supplementation}

Out of 10 interviewees, 7 sustained that requesting a blood test was the most common control practice to assess the level of success of iron supplementation, particularly for therapeutic purposes. A half of pediatricians agreed on requesting a control blood count 2-3 months after treatment initiation. Others, however, considered that asking the mother how the iron was working was adequate as a control strategy. Exceptionally, a few participants explicitly mentioned the guideline on iron deficiency anemia of the

TABLE 2. Opinions from interviewed pediatricians regarding childhood anemia diagnosis using a blood test

\begin{tabular}{|c|c|}
\hline \multicolumn{2}{|c|}{ Anemia diagnosis using a blood count } \\
\hline It is an accidental finding & It is not part of routine practice \\
\hline $\begin{array}{l}\text { "...in general, we order lab tests for something else and it } \\
\text { always shows up". }\end{array}$ & $\begin{array}{l}\text { “...as a rule I don't order the lab test, I think it's too grueling } \\
\text { to ask for a lab test just in case". }\end{array}$ \\
\hline $\begin{array}{l}\text { "...many times, you order a lab test for something else and, } \\
\text { well, you find the patient has a rather severe anemia". }\end{array}$ & $\begin{array}{l}\text { "I don't order them as part of the routine, like other health } \\
\text { care providers, a blood count once a year, I rely on the clinical } \\
\text { situation". }\end{array}$ \\
\hline $\begin{array}{l}\text { "...when they come to the hospital for any other reason and } \\
\text { have lab tests done, their iron is low, their hematocrit is low, } \\
\text { and their hemoglobin is low". }\end{array}$ & $\begin{array}{l}\text { "I don't order them as often for patients younger than } 2 \\
\text { years". }\end{array}$ \\
\hline $\begin{array}{l}\text { "...I mean, maybe you order a lab test for some other } \\
\text { condition and they come back anemic". } \\
\text { "If you ask for lab tests as part of a checkup or if they go to } \\
\text { the emergency room for a fever or some other reason, you } \\
\text { sometimes detect it..." }\end{array}$ & $\begin{array}{l}\text { "...I sometimes order a control lab test; in our setting } \\
\text { sometimes, it's not that there is no access... there is access to } \\
\text { lab tests and all, what we don't see sometimes is maternal } \\
\text { adherence to do the lab test early". }\end{array}$ \\
\hline $\begin{array}{l}\text { "Many times anemia is detected in lab tests ordered in the } \\
\text { emergency room. So I see a hospital blood count and there I } \\
\text { see low hematocrit levels in infants younger than } 1 \text { year old". } \\
\text { "...I don't check them as part of the routine". }\end{array}$ & \\
\hline
\end{tabular}


Argentine Society of Pediatrics (SAP)..$^{13}$

Most interviewees described some difficulty to control iron supplementation in the long term. Among other barriers, it is worth noting a lack of maternal adherence, ferrous sulfate availability as a single alternative at no charge, and limitations to perform blood tests in children.

\section{Considerations about the findings of a study on childhood anemia and iron supplementation conducted in Rosario ${ }^{6}$}

After hearing the following statement: "the overall prevalence of anemia in the sample of children was $40 \%$ and it increased up to $56 \%$ in the 6-23 month-old group", most interviewees (27/32) agreed that it was possible that the prevalence was really as high. All interviewees agreed with the following study finding: "maternal adherence to iron supplementation recommendations is a protective factor against anemia in their children". A large number of participants (27/32) agreed with one of the two most common causes for lack of adherence referred by mothers in the local study: "gastrointestinal intolerance and forgetfulness". More than a half of pediatricians $(19 / 32)$ considered that this situation was closely related to the type of iron available in the public system ("...I don't know if I'd call it intolerance because some mothers say 'it tastes funny and my child doesn't want to take it' or 'my child vomits after taking it,' and it's not that the ferrous sulfate causes them to vomit, it's because it tastes bad, because they grumble when taking it... I wouldn't know if it's a matter of gastrointestinal intolerance", interview no. 8; “... as I said before, in my opinion it has to do with iron flavor, specifically how hard it is for the mother to give it. Well, what I also sometimes do is to explain that the first days the child may have constipation, diarrhea, or they may notice their stools have other characteristics, so that they don't get scared and don't stop giving it because of this, so I basically believe that the problem with giving it is its flavor, and forgetfulness, well, that's a matter of distraction", interview no. 2). Some participants $(13 / 32)$ referred to the importance of making sure that mothers understood the benefits of treatment compliance ("...it's like we've been always working on anemia and, probably, when we tell the mother that their child has anemia, we should probably spend more time explaining the importance of treatment... I mean, we do it but we should probably take more time to work on this issue", interview no. 3).

The range of ideas expressed by interviewees regarding how to improve PHC was broad (see Annex 2). Workshops demonstrated to be an adequate place to address the multiple facets of anemia in the short term and based on available resources.

Based on the interpretation of collected information, we show the relationship among key elements regarding the problem under study (Figure 2).

\section{DISCUSSION}

Based on the findings of a study conducted at the public health network of Rosario, ${ }^{6}$ which showed an association between maternal adherence to iron supplementation and the risk of anemia among children, we decided to use qualitative methods to deepen knowledge

TABLE 3. Summary of explanations in association with the indication of ferrous sulfate referred by interviewed pediatricians

\begin{tabular}{l|l}
\hline \multicolumn{1}{c}{ Oral ferrous sulfate supplementation } \\
\hline \multicolumn{1}{c}{ Anemia prophylaxis } & \multicolumn{1}{c}{ Anemia treatment } \\
\hline $\begin{array}{l}\text { Improvement of gastrointestinal absorption } \\
\text { - Administer with fresh orange juice }\end{array}$ & $\begin{array}{l}\text { Improvement of gastrointestinal absorption } \\
\text { - Administer with fresh orange juice or water } \\
\text { - Administer on an empty stomach or away from } \\
\text { breastfeeding, milk and food intake }\end{array}$ \\
$\begin{array}{l}\text { Potential side effects } \\
\text { - Unpleasant taste }\end{array}$ & $\begin{array}{l}\text { Dietary guidelines } \\
\text { - Iron-rich diet (lentils, chard, spinach, blood sausage, } \\
\text { - Vomiting, diarrhea, constipation, abdominal cramps, } \\
\text { dark colored stools }\end{array}$ \\
- Stains on clothes & $\begin{array}{l}\text { Vitamin supplementation } \\
\text { - Administer folic acid and /or multivitamins }\end{array}$ \\
Dosage & $\begin{array}{l}\text { Dosage } \\
\text { - Once or twice daily }\end{array}$ \\
\hline
\end{tabular}


from the PHC perspective. In the absence of a hypothesis for this subject matter, it could be said that interviewed pediatricians share a common view of anemia and iron supplementation.

The predominant statement was that iron deficiency anemia is a relevant health problem. The findings of this study lead to believing that interviewed pediatricians are in line with national standards; however, diagnostic interventions have a lower hierarchy. Once such concept is conceptualized, clinical conduct translates into the prescription of iron supplementation. In addition to the conditions typically known as predisposing factors for anemia, other risk situations are observed, such as anemia during pregnancy and the family's eating habits. In this circumstance, besides biological risk factors inherent to early childhood, anemia may be traversed by contextual factors. One of the best examples of the need for a more comprehensive approach is the lack of objection -especially in the case of no antenatal controls or inability to assess maternal nutritional status - to the protective role assigned to exclusive breastfeeding in anemia prevention.
In relation to the difficulties associated with iron administration, positions describing protection of the maternal role were observed. On the one side, low maternal adherence may be (largely) explained by the unpleasant taste of ferrous sulfate. On the other side, mothers are probably not duly or adequately informed on the importance of administering iron. In addition, it has been noted that the opportunities to discuss the consequences of iron deficiency on children's growth, immune status, and nervous system development ${ }^{14,15}$ during the pediatric office visit are scarce. These findings are in line with the suggestions made by interviewees and for which there are two clear underlying intentions: to minimize iron rejection and to extend health prevention strategies. Thus, for example, we find the idea of taking advantage of other health care settings that, although outside the office, are considered favorable to address key aspects of iron deficiency anemia in the mother and child population. In this regard, workshops become activities coordinated by the health care team with an active participation of physicians.

This study has served to know primary health

FIGURE 2. Relationship flowchart of maternal adherence to ferrous sulfate supplementation and potentially useful local strategies to improve it at the primary health care level

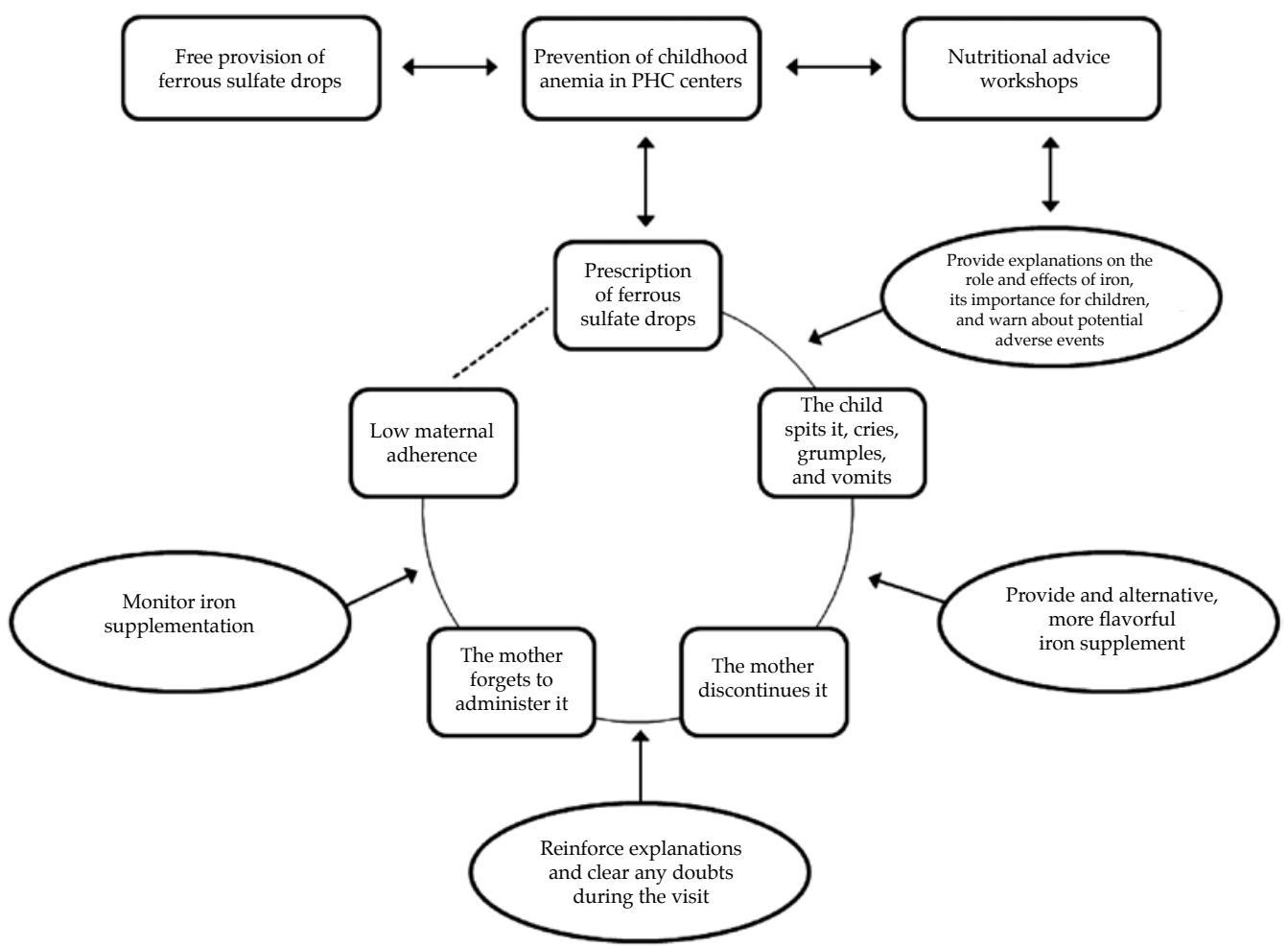

Source: author (April 2016). PHC: primary health care. 
care pediatricians' perspectives about childhood anemia. However, given the uniqueness of interviews, it is not possible to warrant access to a more generalized knowledge.

Some of the limitations of this study are that we did not interview family physicians working in pediatric care at participating centers and the lack of investigation of a key subject matter such as the diagnosis of infant anemia. It is also worth noting that it was not possible to make comparisons with other studies.

Although it is not possible to extrapolate the outcomes of qualitative studies to a specific population, the resulting evidence should be considered an advance in the investigation of barriers for the implementation of interventions in the local public health setting while waiting for future studies regarding new interpretations or hypotheses.

It would be interesting to know the opinions, motivations, circumstances, etc. of mothers and families attending primary care health centers.

\section{CONCLUSIONS}

Iron deficiency anemia occupies a prevalent place as a pediatric health problem in the primary health care setting. As described by pediatricians, among other potentially beneficial strategies for the local setting, it is worth mentioning workshops on anemia and access to more flavorful iron supplements.

\section{Acknowledgments}

We are grateful to the pediatricians from the city of Rosario who participated in this study. We would like to thank the National Ministry of Health, the Center for Perinatal Studies of Rosario (Centro Rosarino de Estudios Perinatales, CREP), and the Municipal Department of Primary Health Care of Rosario for their support to carry out this investigation. Also, we would like to thank Alicia Aronna, Master of Public Health and Statistics, for her comments regarding the manuscript, and the external reviewers who have anonymously contributed to improve the manuscript's quality.

\section{REFERENCES}

1. Benoist B, Mclean E, Egli I, et al. Worldwide prevalence of anaemia 1993-2005: WHO Global Database on Anaemia. World Health Organization; 2008. [Accessed on: May 31 $\left.{ }^{\text {st }}, 2016\right]$. Available at: http://whqlibdoc.who.int/ publications / 2008/9789241596657_eng.pdf.

2. World Health Organization. Iron deficiency anaemia. Assessment, prevention and control. A guide for programme managers. WHO/NHD/01.3. Geneva: WHO. 2001. [Accessed on: May 31 ${ }^{\text {st }}, 2016$ ]. Available at: http: / / apps.who.int/iris / handle/10665/66914.

3. Stoltzfus RJ, Dreyfuss ML. Guidelines for the Use of Iron Supplements to Prevent and Treat Iron Deficiency Anemia. International Nutritional Anemia Consultative Group (INACG). [Accessed on: May 31 ${ }^{\text {st }}$, 2016]. Available at: http: / / www.who.int/ nutrition/publications / micronutrients/guidelines_for_Iron_supplementation. pdf.

4. Lineamientos de prevención y tratamiento de la anemia en la población materno infantil. [Accessed on: May 31 ${ }^{\text {st }}$, 2016]. Available at: http://www.ms.gba.gov.ar/sitios/ seguropublico / files / 2012/03 / Lineamientos-anemia.pdf.

5. Durán P, Mangialavori G, Biglieri A, et al. Estudio descriptivo de la situación nutricional en niños de 6-72 meses de la República Argentina: resultados de la Encuesta Nacional de Nutrición y Salud (ENNyS). Arch Argent Pediatr2009;107(5):397-404.

6. Christensen L, Sguassero Y, Cuesta CB. Anemia y adherencia a la suplementación oral con hierro en una muestra de niños usuarios de la red de salud pública de Rosario, Santa Fe. Arch Argent Pediatr2013;111(4):288-94.

7. Bernztein R. El hierro, la anemia, y el uso racional en el Programa REMEDIAR. AtenciónPrimaria de la Salud. Boletín PROAPS Remediar2003;1(4):4-7.

8. Bernztein R, Drake I. Subprescripción de hierro y variabilidad en el primer nivel de atención público de la Argentina. Arch Argent Pediatr2008;106(4):320-7.

9. Sanmartino G. Representaciones culturales acerca de la anemia y la suplementación con hierro. Arch Argent Pediatr2010;108(5):401-8.

10. Tarrés ML. Observar, escuchar y comprender sobre la tradición cualitativa en la investigación social. México: FLACSO/El Colegio de México, 2014.

11. Ulin PR, Robinson ET, Tolley EE. Investigación aplicada en salud pública. Métodos cualitativos. Publicación científica y técnica N. ${ }^{\circ}$ 614. Washington: OPS; 2006. [Accessedon: May 31 ${ }^{\text {st }}$ 2016]. Available at: http://apps.who.int/iris / bitstream/10665/166144/1/9275316147.pdf.

12. Informe de resultados: Satisfacción profesional de Médicos Pediatras. Sociedad Argentina de Pediatría-UNICEF;2011. [Accessed on: May 31 st, 2016]. Available at: http: / / www. sap.org.ar/docs/Present_SAP_UNICEF.pdf.

13. Comité Nacional de Hematología. Anemia Ferropénica. Guía de diagnóstico y tratamiento. Arch Argent Pediatr2009;107(4):353-61.

14. Olivares M, Walter T. Consecuencias de la deficiencia de hierro. Rev ChilNutr2003;30(3):226-33.

15. Lozoff B. Iron deficiency and child development. Food Nutr Bull 2007;8(Suppl 4):S560-71. 


\section{ANNEX 1 Interview guide}

1. We all say that childhood anemia, "particularly that associated with iron deficiency," is a health problem in Argentina. I would like to know your personal opinion in this regard.

Complementary questions:

* I would like to know if you agree with the fact that childhood anemia is considered a health problem in Argentina.

* Please, could you tell me why you agree? If you think this is a problem, why do you think so? Please, could you tell why you disagree?

1.1 In your opinion, which children are at a greater risk of having anemia?

1.2 Based on your personal experience working at this primary health care center, (approximately) what percentage of children younger than 2 years have anemia?

2. For example, which clinical situations (clinical cases) would lead you to prescribe iron supplementation to "prevent" anemia in a child?

2.1 Let us go over an example of prevention you mentioned in the previous question. So, what indications do you give to the mother of a child who has to take iron to "prevent anemia"?

Complementary question:

* What recommendation or explanation do you give to the mother of a child who has to take iron for prevention?

2.2 Now we have the case of a child diagnosed with iron deficiency anemia, what indications do you give to the mother who has to give iron (or ferrous sulfate, if the physician has mentioned it) as a treatment for her child?

Complementary questions:

* What indications do you give for the administration of iron supplementation to the mother of a child diagnosed with anemia?

* What recommendation or explanation do you give to the mother of a child who has to take iron because he/she has anemia?

2.3 Now, let us suppose you gave the indications to the mother of a child who has to take iron (or ferrous sulfate, if the physician has mentioned it) in a timely manner: how do you usually control the supplement's effect on the child?

2.4 In relation to your answer, I would like to ask you: what kind of barriers/hurdles do you see in your office when trying to monitor children's compliance with oral iron supplementation?

Complementary question:

* In relation to what you said, could you please give me an example?

3. Now, I would like to share with you the outcomes of a local study ${ }^{1}$ on anemia and maternal adherence to oral iron supplementation in their children conducted in health centers from Rosario between December 2011 and April 2012.

Data from a sample of approximately 320 mother-child dyads were analyzed; children were younger than 3.5 years and had a hemoglobin rapid test as part of data collection in the field (in addition to other sociodemographic outcome measures, medical history, growth and development). I will read the main findings of this study and then I will ask you to comment on them.

3.1 The first finding was: "The overall prevalence of anemia was 40\%, and it increased up to $56 \%$ in the 6-23 month old group." That is to say, 1 in 2 children in this age group had a hemoglobin level lower than expected based on the rapid test result. What do you think about this percentage of children with anemia?

3.2 Another finding was: "83 mothers (out of the 325 included in the study) administered iron to their children. In this sub-group of mothers, adherence to iron administration was higher among those whose children did not have anemia than those whose children had anemia." This means that the fact that mothers adhered to iron supplementation recommendations is a protective factor against anemia in their children. What do you think about this finding?

Complementary question:

* Is this different than what you perceive/observe in your office?

3.3 The last finding was: "The most common causes for lack of adherence referred by mothers included gastrointestinal intolerance $(38 \%)$ and forgetfulness (36\%)." Do you have any other explanation for maternal lack of adherence?

Complementary question:

* That is to say, in your opinion, is there any other reason why mothers do not follow their pediatrician's indications?

4. Is it $\mathrm{OK}$ if we now move to the last question?

4.1 OK, based on what we have discussed here, in your opinion, what could the health care team working in this center do to encourage adherence among the mothers who have to administer iron to their children? Would you like to add anything?

Thank you for your time and for the information you are providing!

1. Christensen L, Sguassero $Y$, Cuesta CB. Anemia y adherencia a la suplementación oral con hierro en una muestra de niños usuarios de la red de salud pública de Rosario, Santa Fe. Arch Argent Pediatr2013;111(4):288-94. 


\section{ANNEX 2}

Suggestions made by interviewed pediatricians to improve maternal adherence to iron supplementation in their children based on different settings.

Suggestions to improve maternal adherence to iron supplementation in their children

\begin{tabular}{l}
\hline Pediatrics office \\
\hline “...to me the other thing is... a \\
highlevelof reciprocity with the \\
mother is necessary, even if you \\
do lots of things, if you don't \\
establish reference and trust \\
with the mother, even if you \\
put up signs and implement \\
programs..."
\end{tabular}

“....an office practice, where this is established as a priority, and a follow-up practice."

"Reinforceit during office visits, the importance of giving it, the importance it will have on their growth and development... trying to make sure the mother understands... that anything her child misses at this stage of development, he/she will not recover when he/she grows up."

"... at each visit, you have to insist on iron administration, that you cannot give it at 2 or 4 months and that's it because it doesn't work, you have to insist and insist, in each visit."

"...using medical records is critical... handwriting should be clear, and it should be documented that that child has to receive prophylaxis for anemia as of 3 months old..."

"You have to get the father involved... If both agree it is much easier to maintain iron treatment because it is prolonged and they have to remember."
Primary health care system

Health center
"...itis necessary to strengthen
the bond between the health
center and the family
so that they adhere
to anything."

"I also believe you could reinforce this with the help of the nursing department, Idon't know, when they go there to get a vaccine at 4 months old, well, to reinforce it and know whether the mother is giving the iron or not."

“...work team, healthy eating, healthy lifestyle."

“...so, sometimes promotion and prevention activities lose the relevance and importance they should have in health care."

“...you order for a control lab test but in my practice, I see that many times they don't do it or if they do, I never get to see the results... I mean, probably because this place is organized as a health center, you see lab results first and then add a note: $\mathrm{OK}$, come and talk to the doctor."

“...discussions in the waiting room, when a lot of mothers are there."

"Yes, probably have briefings with the mothers of infants younger than 1 year or 2 years and explain..."

"We have a mechanism for mothers and children younger than 3 years that works on Mondays and we could work on this issue with this population attending the center weekly."

Public health care network

"In the public health field it is necessary to create awareness among pediatricians..."

“...statistics and knowing data about our population."

"...probably a method that is not invasive... so that you don't have to use needles in the children, it would be really good to improve detection."

"We should all agree when and how to giveit, and all that stuff... and also organize it because you may say it and then have no written material to give to the mother and so that we don't have to write down everything, the indications, I mean, how to improve absorption and all that..."

“...signs, for example, about anemia or information for promotion..."

"...a campaign at the public health level... greater dissemination of the actual importance of iron for everything, learning that it is vital for all organs."

"...having a campaign on anemia prevention."
"We could go to the Local Communal Center, where young children go, and talk to their mothers about the importance of giving them iron on the day of the week that they all come together..."

“...probably a campaign to work with the mass media to reach more people... reinforce the importance of eating, growing healthy..."

"I think we should also focus on food, children's diet, because it seems they have a poor diet since they are 6 months old, it has to do with culture, TV announcements, but I think that more and more children have a poor diet, worse than before."

“...organize walks, something to do with physical exercise and also bring back the idea of having a vegetable garden." 
III / Arch Argent Pediatr 2018;116(1):21-27 / Original article

"Yes, I guess having workshops would help a lot to the relationship and general health problems because it brings the health care team and the community together, and it's a more informal setting, outside the office and that alone is very helpful, besides mothers may exchange ideas about their habits and experiences so that they see they are not alone, that many of their peers are going through the same or something similar, that would be ideal, having workshops."

"Workshops on healthy eating and where healthy eating means including iron as part of the diet, which foods are sources of iron, what it is good for..."

"Here we have a workshop for pregnant women, we could probably include a pediatrician who tells mothers during pregnancy already."

"I also work on a workshop, I have a pediatrics workshop once a month where we work on... the problem has to do with teenage mothers... so we work hard on this, eating, iron intake, whether they are doing it, it's a place outside this all." 